\title{
Erratum to: Provider and Staff Perceptions and Experiences Implementing Behavioral Health Integration in Six Low-Income Health Care Organizations
}

\author{
Heather Farb, MPH \\ Katie Sacca, MPH \\ Margaret Variano, MPH \\ Lisa Gentry, LMSW, MPH \\ Meagan Relle, MPH, MBA \\ Jane Bertrand, PhD, MBA
}

\author{
Erratum to: J Behav Health Serv Res \\ http://dx.doi.org/10.1007/s11414-017-9559-6
}

In the published article, the affiliation information for Katie Sacca is not accurate. There is an outdated and unnecessary email address. Her additional affiliation, Louisiana Public Health Institute, is not listed. The accurate affiliation information for Katie Sacca appears below.

At the time this paper was being written, Katie Sacca, Margaret Variano, and Lisa Gentry were affiliated with Louisiana Public Health Institute.

Address correspondence to Heather Farb, MPH, Louisiana Public Health Institute, 1515 Poydras Street, Suite 1200, New Orleans, LA 70112, USA. Email: hfarb@lphi.org.

Katie Sacca, MPH, Louisiana Public Health Institute, New Orleans, LA, USA.

Margaret Variano, MPH, Louisiana Public Health Institute, New Orleans, LA, USA.

Lisa Gentry, LMSW, MPH, Louisiana Public Health Institute, New Orleans, LA, USA.

Meagan Relle, MPH, MBA, Louisiana Public Health Institute, New Orleans, LA, USA.

Katie Sacca, MPH, Louisiana Department of Health, Office of Public Health, Bureau of Family Health, New Orleans, LA, USA.

Margaret Variano, MPH, Ochsner Health System, Jefferson, LA, USA.

Lisa Gentry, LMSW, MPH, Optum, Metairie, LA, USA.

Jane Bertrand, PhD, MBA, Department of Global Health Management and Policy, Tulane School of Public Health and Tropical Medicine, New Orleans, LA, USA.

The online version of the original article can be found at http://dx.doi.org/10.1007/s11414-017-9559-6

Journal of Behavioral Health Services \& Research, 2017. 156. (c) 2017 National Council for Behavioral Health. DOI 10.1007/s11414-017-9566-7 